\title{
MATHEMATICS STUDIES AT UNIVERSITY: EFFECT ON THE PROFESSIONAL COMPETENCE
}

\author{
Anna Vintere \\ Anda Zeidmane \\ Latvia University of Agriculture
}

\begin{abstract}
It is known that mathematics has an impact on the development of the professional competence both directly (serves as a tool for solving and calculating various problems) and indirectly (promotes logical thinking, develops skills to formulate and solve problems etc.). To identify importance of mathematics studies in the development of professional competence in assessment of graduates the research was done by Latvian University of Agriculture and Siauliai University in the framework of Latvian-Lithuanian cross-border cooperation program's project „Cross-border network for adapting mathematical competences in the socio-economical development". A questionnaire based research was the part of this research. The survey results obtained in Latvia are analysed in this article and include the following aspects: mathematics in professional practice and need for improvement of mathematical knowledge and assessment of practical potential of mathematics.
\end{abstract}

Keywords: mathematics, mathematical thinking, mathematics study process, practical potential of mathematics.

\section{Introduction}

In this new era of knowledge and creative society, there is a need and importance to prepare intellectual professionals and specialists for the labour market. Because of changes in the social, technological, educational and other environments, the information, knowledge and skills become older very quickly, so there is a constant need for lifelong learning and permanent renewing of acquired skills. It is obvious that changes, which are seen in society, require changes in higher education institutions, too. Higher education institutions have new approaches towards teaching and learning paradigms. Learning becomes a process in which people develop their knowledge, understanding, skills, values, attitudes and experience.

An important indicator for development of higher education is a labour market. Employers believe that university graduates should focus on a broad spectrum of new technologies. A good specialist is the one who is able not only to adapt to changes and to improve (or even change) its qualifications, but can be the originators of innovations (Dimza, 2003). In addition, graduates must be prepared to work in a modern organization, which is characterized by a continuous process of innovation, customer centricity, the resignation of the old, working in teams, etc. (Drucker, 1994). And so, universal and sustainable skills, which will be useful for various areas of professional activity in the long-term period, are important both for production and the university education (Radcliffe, 2006).

Mathematics is a discipline which is required as a background for specialists who work in the environmental protection, engineering, construction, business, 
telecommunication, textile, new energy sources, etc. Mathematics as a discipline has been taught in schools, colleges, vocational training and universities and has an impact on the development of the professional competence both directly (serves as a tool for solving and calculating various problems) and indirectly (promotes logical thinking, develops skills to formulate and solve problems etc.). Mathematics can be regarded as a tool for analysing problems that occur in the world in general and, therefore, as a tool for solving them, as well as something which co-exists with other areas of knowledge and supports the study and development of that knowledge. Therefore, the aim of the article is to explore the role of mathematics in higher education as well as to identify the importance of mathematics studies in the development of professional competence in assessment of graduates.

The research on external demands of labour market and employers was done by Latvian University of Agriculture (in cooperation with Siauliai University) in the framework of Latvian-Lithuanian cross-border cooperation program's project "Cross-border network for adapting mathematical competences in the socio-economical development". In this article the survey results are analysed regarding compliance of mathematical and professional competence obtained in Latvia. Thus focus of this study is on the employers' and the employees' survey results. The article also includes theoretical analysis of topical issues like the understanding of the notion of professional competence and mathematical competence as well as describes specific characters of the mathematics.

\section{Methodology of research}

The problem has been approached by analysing and evaluating the scientific literature for the development of the methodological basis of research. Empirical study was done based on questionnaire, designated to employees with higher education. The purpose was to reveal the opinion of employed people about various aspects of the application of mathematics in professional activities. The questionnaire form includes five diagnostic blocks. In this paper the results are analysed from two diagnostic blocks: "Mathematics in professional practice and need for improvement of mathematical knowledge" $(\mathrm{N}=9)$ and "Assessment of practical potential of mathematics" $(\mathrm{N}=5)$. There were 14 questions presented. The respondents had to assess the statements by expressing their approval or disapproval on a 4-stage Likert scale: strongly agree, agree, disagree, and strongly disagree. The total sample of the research in Latvia included 307 cases. The sample is dominated by those respondents who have completed university only 1-5 years ago. The distribution between the genders is similar. Almost onefourth of respondents have a master's degree, but the third part of the respondents has a higher vocational education. The survey involved more than one-third who studied engineering at university but one sixth of the respondents have studied technological sciences. The number of respondents who have studied humanities and arts or social sciences is similar (nearly one-sixth). 


\section{Understanding of the notions of professional competence and mathematical competence}

In the 21 st century the use of knowledge and skills at work/ action has become one of the cornerstones of the comprehension of the competence. Competence is the one that determines the ability to use the acquired in action and to complete it, the ability to work with the knowledge, skills and existing attitudes, use and consummate them. Competence is also viewed as an ideal of education, and it can be defined as combination of individual skills and experience that is based on the opportunities to gain experience.

Competence can be explained as actions that are necessary to demonstrate and precisely measured result (Strebler at al, 1997; Hoffmann, 1999 from Boam and Sparrow, 1992, Bowden and Masters, 1993). It is so called behavioural approach. It also includes standard requirements that are necessary to execute; qualitative result with previously determined level to achieve (Strebler at al, 1997; Hoffmann, 1999 from Rutherford, 1995, Hager et. al., 1994). Outcomes are determined by company goals, tasks and strategy. The third approach is concentrated on the development of personality. It combines social, cognitive and emotional field and includes such elements of competence as knowledge, skills, attitudes; concentrating on the input of personality in general to consummate competences. That is ability to acquire and responsibly use knowledge and skills and attitude in the action, and this ability can be judged after definite criteria.

Reetz (Reetz 1999, 2003) divides competence the following: professional, methodical, social and self-competence. While Garley (2006) structures competence in three ways: professional, social and competence of individual development or socially-cultural competence.

Bader (1990) characterises professional competence as an ability and readiness to act accordingly in the professional situations, personally planning and socially taking the responsibility. It means being able to find solution based on knowledge, experience, own ideas, and be able to both evaluate, and develop this solution, in that way, developing the ability of own action. According to Keller and Novak, professional competence is a relationship between the components of competence in a specific professional field to accordingly act out the tasks (Keller, Novak, 1993).

Nowadays professional competence can be described also by the problem solving and design skills. Problem solving outcome means that specialists will be able to identify, formulate, and solve a problem and evaluate the effectiveness of the solution. Assessing situations, formulate alternatives and recommend feasible solutions - are the most important aspects of the professional competence for the specialists in any field. Design outcome means that specialists will be able to evaluate the design of a complex system, component, or process to ensure that it meets a client's needs and accounts for 
all relevant constraints. Critical design methodology and process elements include problem definition, scope, analysis, risk assessment, environmental impact statements, creativity, iteration, regulations, codes, safety, security and constructability, sustainability and multiple objectives and various perspectives (Walesh, 2006).

Mathematics studies at the university have direct impact on the development of the professional competence. Mathematics serves as a tool for solving and calculating various problems and outcome means that specialists will be able to solve problems in mathematics through differential equations, calculus-based etc. (Walesh, 2006).

During the mathematics studies students and teachers work at acquisition of several skills of different nature (mainly cognitive abilities), e.g., mathematics has also indirect impact on the development of professional competence. Firstly, it is the skills to apply formal rules exactly, which are sometimes abstract, complicated and multi-graded. An important skill is to choose exactly the rule which is necessary from a long list of known rules to complete the task, to design a solution plan or to design a sequence for applicable rules. Management skills are being developed here. Demonstrations of different theorems are significant in the mathematics study process. Acquiring demonstrations, students develop skills of logical conclusions. The ability to transfer the constructive solution of the problem to a real situation is very important as well (Zeidmane, Sergejeva, 2013). It should be noted that usually various standardised, algorism working instruments and procedures are based on the knowledge of mathematics.

In both cases (direct and indirect impact) discussed concept "Mathematical competence". What does it mean to possess mathematical competence? According to Niss (Niss, 1999, 2003) to possess a competence (to be competent) in some domain of personal, professional or social life is to master essential aspects of life in that domain. Mathematical competence then means the ability to understand, judge, do, and use mathematics in a variety of intra- and extramathematical contexts and situations in which mathematics plays or could play a role. Necessary, but certainly not sufficient, prerequisites for mathematical competence are lots of factual knowledge and technical skills.

According to Niss (Niss, 1999) there are eight competencies which can be said to form two groups. The first group of competencies are to do with the ability to ask and answer questions in and with mathematics: thinking mathematically (mastering mathematical modes of thought), posing and solving mathematical problems, modelling (i.e. analysing and building models) and reasoning mathematically. The other group of competencies is to do with the ability to deal with and manage mathematical language and tools: representing mathematical entities handling mathematical symbols and formalisms, communicating in, with, and about mathematics and making use of aids and tools. 


\section{Research results}

By tradition, the subject of mathematics at university has a high status. It is considered difficult to learn and yet, often without any detailed justification, it has a high value. Few people are indifferent to the subject - they either found it easy or have a good appreciation of its content, or they have feelings of anxiety, and possibly disassociation, which may be attributed to the failures and learning blockages from their school years. Therefore since the subject of Mathematics increasingly becomes an instrument for promoting broad all-round education and personal development, many education courses are mathematics-intensive, students need a high level of competence in the subject (Gustafsson, Ouwitz, 2004). The results from empirical research suggest that mathematics in Latvia also has high status and graduates assess its potential value.

The diagnostic block "Mathematics in professional practice and need for improvement of mathematical knowledge" consists of nine statements (Figure 1) which include two aspects of mathematics in professional activities: mathematics in a particular professional environment and an interest in deepening mathematical knowledge in the professional area. 56\% of respondents would like to attend the training that deals with application of mathematics to solve practical problems of their professional field.

The key conclusion drawn from this block is that mathematics in a particular professional environment is quite important. More than $68 \%$ of respondents agree or strongly agree that the knowledge and abilities of mathematics, mathematical thinking helped them to achieve more in their life as well as they understand mathematical symbols and a formal mathematical language which is used in their professional literature.

The advantage of mathematics knowledge on the labour market is characterized by the answer to the question: "A person who understands mathematics will easily master most jobs that require thinking" and "People who understand mathematics well are highly assessed by employers", positive responses are similar $(65 \%, 59 \%)$.

Teaching of mathematics at higher education school is usually criticised for insufficient correlation between the theory and practice. However, the survey demonstrated that $68 \%$ of the respondents agreed with the statements expressing the relevance of mathematics analysing the problems of the real world.

Viewpoint of the opportunities to use mathematical knowledge is similar for both women and men. But the results indicate that the widest possibility to use mathematical knowledge in their professional activities was for economists as well as for workers in banks and in the area of information technology, but the least opportunity to apply mathematical knowledge was for workers in the mechanical engineering. In general, the respondents think that mathematics is the most widely used in construction, but least - in agriculture. 
I would like to attend the training that deals with math application to solve the practical problems of my professional field

I understand math symbols and a formal math language which is used in my professional literature

A person who understands math will easily master most jobs that require thinking

Mathematical thinking helps to solve real world/ professional problems

Math is widely used in my professional activities

My occupation does not require deeper knowledge of math: it is enough to do arithmetical calculations and count percentage

I have a lot of opportunities to apply my knowledge of math in professional activities

People who understand math well, are highly assessed by employers

The knowledge and abilities of math, mathematical thinking helped me to achieve more in my life

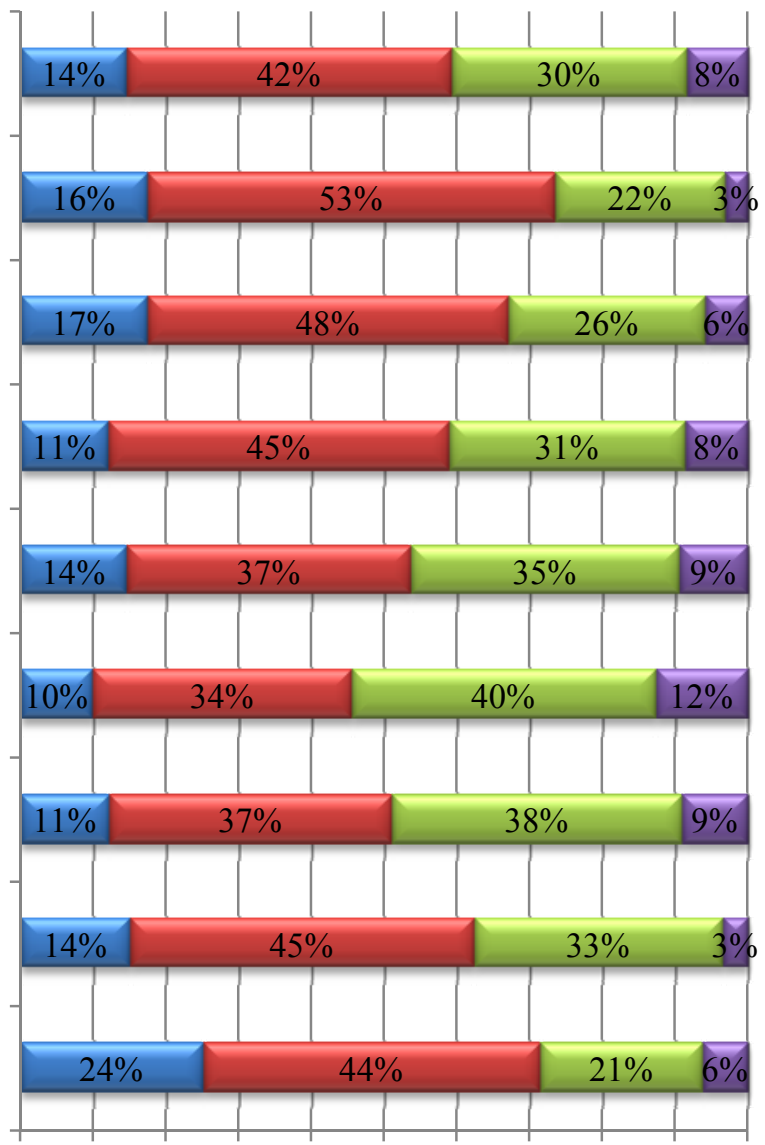

0\% 10\% 20\% 30\% 40\% 50\% 60\% 70\% 80\% 90\%100\%

$\square$ Strongly agree $\square$ Agree $\square$ Disagree $\square$ Strongly disagree

Figure 1. Mathematics in professional activities

Next diagnostic block consists of four statements which include several potential values of mathematics: problem-solving tool, thinking education tool, meaningless engagement, a subject revealing human potential in working activities.

This block highlights the essence and importance of mathematics by the impact of mathematics to the professional competence - $70 \%$ of the respondents emphasided that mathematics develops thinking, helps to make a decision in a particular situation, to find new ideas.

The essence and importance of mathematics are characterized as well by answers: Mathematics helps to model and analyse the problems of the real world (74\%) and Mathematics gives an insight into the world we live (63\%).

It should be noted that men noted the essence and importance of mathematics twice more often than women. 


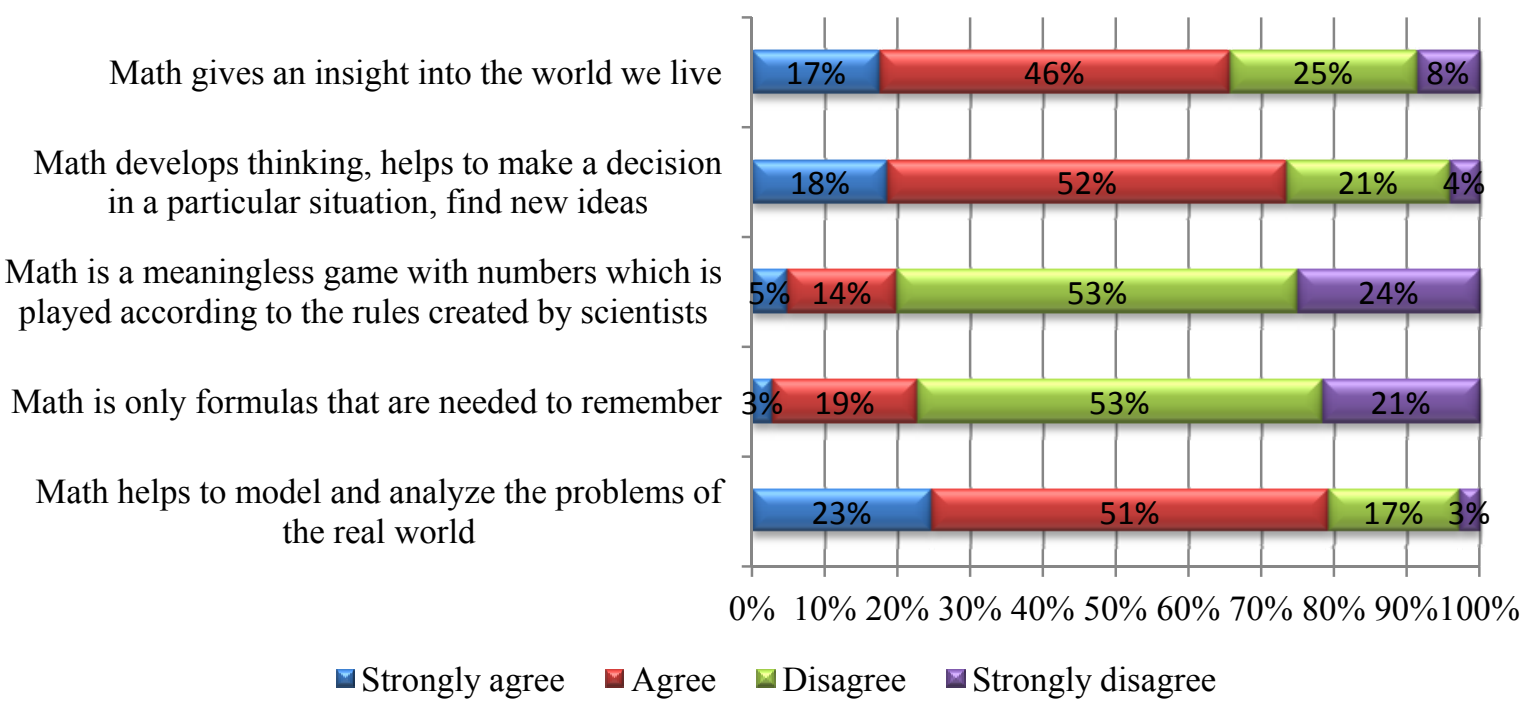

Figure 2. Assessment of practical potential of mathematics

\section{Conclusions}

1. The results of this research show that mathematics has a high status and include several potential values of mathematics:

a. Problem-solving and thinking developing means;

b. It is a tool for describing the real world and revealing human potential in working activities.

2. The role of mathematics in promoting professional competence:

a. Mathematics develops logical thinking, accuracy and concreteness of future specialists;

b. Mathematics helps to make a decision in a particular situation, to find new ideas.

3. The advantage of mathematics knowledge on the labour market:

a. A person who understands mathematics will easily master most jobs that require thinking;

b. People who understand mathematics well are highly assessed by employers.

4. There are correlation between mathematics and professional activities:

a. Mathematics helps to model and analyse the problems of the real world;

b. Mathematics gives an insight into the world we live.

5. Results show that a very large number of respondents have an interest in deepening mathematical knowledge:

a. That is why universities and colleges need to offer a variety of lifelong learning programs in mathematics;

b. It should be noticed that this need was strongly related to the situation of the application of mathematics in their professional activities. Therefore, the applications of mathematics should be an integral part of the content 
of professional development both to the specialists who apply mathematics directly in their work and the ones who see a possibility to apply it.

\section{References}

1. Dimza V. (2003). Inovācijas pasaulē, Eiropā, Latvijā (Innovations in the world, Europe, Latvia). Rīga: LZA EI, 206 lp. (In Latvian)

2. Drucker P.F. (1994). Post Capitalist Society. NY: Harper Business, 232 p.

3. Giroux H.A. (1997). Pedagogy and the Politics and Hope: Theory, Culture and Schooling: a critical reader. USA, Boulder: Westview Press, 290 p.

4. Gustafsson, L., Ouwitz, L. (2004). Adults and Mathematics - a vital subject. ISSN 1650 335X, NCM, 18 p. [online] [24.01.2014]. Available at: http://ncm.gu.se/ media/ncm/rapporter/adult-en.pdf

5. Habermas, J. (2006). Time of transitions. Oxford: Polity.

6. Habermas, J. (2003). The future of human nature. Cambridge. UK: Malden, MA: Polity, 2003.

7. Maslo I., Tilla I. (2005). Kompetence kā audzināšanas ideāls un analītiskā kategorija (Competence as an ideal of upbringing and analytical category). Skolotājs Nr.3, 4.-9. lpp. (In Latvian)

8. Niss, M. (1999) .Kompetencer og uddannelsesbeskrivelse (Competencies and description of education). Uddannelse 9, 21-29 pp. (In German)

9. Niss, M. (2003). Mathematical competencies and the learning of mathematics. The Danish KOM project. Paper presented at the Third Mediterranean conference on mathematics education, Athens.

10. Radcliffe D. (2006). Global Challenges facing Engineering Education: Opportunities for Innovation. Proceedings of the $35^{\text {th }}$ International IGIP Symposium in cooperation with IEEE / ASEE / SEFI, 2006-09-18, Tallinn, Estonia, 15-27 pp.

11. Walesh S. G. (2006). Body of Knowledge for Civil Engineers: Essential for Success in the International Arena. Proceedings of the $35^{\text {th }}$ International IGIP Symposium in cooperation with IEEE / ASEE / SEFI, 2006-09-18, Tallinn, Estonia, 163-178 pp.

12. Zeidmane A., Sergejeva N. (2013). Indirect impact of mathematics in engineering education // Proceedings of $12^{\text {th }}$ International Scientific Conference Engineering for rural development, 2013, May24-25, Jelgava, Latvia, p.611-615.

$\begin{array}{ll}\text { Mg, Math, Aplicant for the } & \text { Latvia University of Agriculture } \\ \text { scientific degree in Education } & \text { Department of Mathematics } \\ \text { Management } & \text { Liela street 2, Jelgava, LV-3004, Latvia } \\ \text { Anna Vintere } & \text { e-mail: Anna.Vintere@llu.lv } \\ \text { Dr.Paed, prof. } & \text { Latvia University of Agriculture } \\ \text { Anda Zeidmane } & \text { Department of Mathematics } \\ & \text { Liela street 2, Jelgava, LV-3004, Latvia } \\ & \text { e-mail: Anda.Zeidmane@llu.lv }\end{array}$

